\title{
Atmosfera modificada em laranja 'Pêra' minimamente processada
}

\author{
Maria Cecília de Arruda $\left({ }^{1 *}\right)$; Angelo Pedro Jacomino $\left({ }^{2}\right)$; Marcos José Trevisan $\left({ }^{2}\right)$; \\ Elisangela Marques Jeronimo (3); Celso Luiz Moretti ( ${ }^{4}$ )
}

(') Agência Paulista de Tecnologia dos Agronegócios (APTA), Polo Regional Centro-Oeste, Av. Rodrigues Alves, 40-40, 17030-000 Bauru (SP).

(2) Escola Superior de Agricultura Luiz de Queiroz, Departamento de Produção Vegetal, Caixa Postal 9, 13418-900 Piracicaba (SP).

(3) APTA, Polo Regional Centro-Oeste, Unidade de Pesquisa de Jaú, Rod. Leônidas Pacheco Ferreira, Km 304, 17201-970 Jaú (SP).

(4) Embrapa Hortaliças, Caixa. Postal 218, 70359-970 Brasília (DF).

(*) Autora correspondente: mcarruda@apta.sp.gov.br

Recebido: 6/jul./2010; Aceito: 23/nov./2010

\section{Resumo}

Este trabalho teve como objetivo determinar a influência da embalagem com atmosfera modificada na manutenção da qualidade de laranja 'Pêra' minimamente processada armazenada sob refrigeração. As laranjas descascadas foram acondicionadas em filme de polipropileno de $32 \mu \mathrm{m}$ sob atmosfera modificada passiva ou ativa $\left(5 \% \mathrm{O}_{2}+10 \% \mathrm{CO}_{2}\right.$; balanço $\left.\mathrm{N}_{2}\right)$. Laranjas acondicionadas em bandeja de poliestireno expandido revestida com filme de cloreto de polivinila de $20 \mu \mathrm{m}$ foram utilizadas como controle. $\mathrm{O}$ armazenamento dos frutos minimamente processados foi realizado a $6 \pm 1{ }^{\circ} \mathrm{C}$ e a $12 \pm 1{ }^{\circ} \mathrm{C}$. Periodicamente, foram realizadas análises químicas, sensoriais e microbiológicas. Foram determinados também os teores de etanol e acetaldeído e a atividade da enzima peroxidase. As variáveis químicas determinadas não foram afetadas pelos tratamentos. Houve apenas efeito do tempo de armazenamento nos teores de sólidos solúveis, os quais se reduziram aproximadamente 10\% ao longo do armazenamento. Os níveis de contaminação microbiológica foram baixos, não diferindo entre os tratamentos. Houve acúmulo de acetaldeído e etanol em função da modificação da atmosfera, não prejudicando, no entanto, o aroma e o sabor dos frutos, que se mantiveram aceitáveis até o final do armazenamento, assim como a aparência. A atividade da peroxidase foi baixa, sem influência dos tratamentos. A embalagem de PVC foi tão eficiente quanto à embalagem de polipropileno sob atmosfera modificada passiva ou ativa, dentro do período avaliado, permitindo a conservação das laranjas por até nove dias a $12^{\circ} \mathrm{C}$ e até 12 dias a $6^{\circ} \mathrm{C}$.

Palavras-chave: Citrus sinensis; atmosfera modificada, refrigeração, temperatura de armazenamento, processamento mínimo, conservação.

\section{Modified atmosphere in minimally processed 'Pêra' orange}

\begin{abstract}
The present work aimed to determine the influence of modified atmosphere packaging on the quality maintenance of minimally processed 'Pera' oranges stored under refrigeration. Peeled oranges were placed on packaging materials and were submitted to the following treatments: (1) control - oranges placed in expanded polystyrene trays covered with PVC film; (2) passive - oranges wrapped in $32 \mu \mathrm{m}$-polypropylene film under passive modified atmosphere; (3) active - oranges wrapped in $32 \mu \mathrm{m}$-polypropylene film under active modified atmosphere $\left(5 \% \mathrm{O}_{2}+10 \% \mathrm{CO}_{2}\right.$; balance $\left.\mathrm{N}_{2}\right)$. Minimally processed fruits were then stored at $6 \pm 1^{\circ} \mathrm{C}$ and $12 \pm 1^{\circ} \mathrm{C}$. Chemical, sensorial and microbiological analyses were carried out periodically. Ethanol and acetaldehyde levels, as well as the peroxidase activity were determined. Chemical variables were not affected by treatments. However, it was observed an effect of storage time on the soluble solids content, which reduced throughout the storage period by $10 \%$. Microbiological contamination levels were low and not affected by treatments. There was an accumulation of acetaldehyde and ethanol due to the modified atmosphere. However, it did not affect fruit flavor, which remained acceptable until the end of the storage period, as well as the appearance. Peroxidase activity was low and not influenced by treatments. PVC film was as effective as the polypropylene one under passive or active modified atmosphere within the period evaluated, with oranges stored at $6^{\circ} \mathrm{C}$ and $12^{\circ} \mathrm{C}$ showing shelf life of 12 and nine days, respectively.
\end{abstract}

Key words: Citrus sinensis, modified atmosphere, refrigeration, storage temperature, minimal processing, conservation. 


\section{INTRODUÇÃO}

Um dos maiores problemas dos produtos minimamente processados é sua rápida deterioração. Os danos mecânicos provocados pelo descascamento, corte e fatiamento propiciam elevação da atividade respiratória e da produção de etileno, especialmente nas primeiras horas após o processamento. A presença de células injuriadas e a perda de componentes celulares durante as operaçôes de processamento favorecem o desenvolvimento de microrganismos. O tipo e a espécie, assim como o nível microbiano nos produtos minimamente processados varia de acordo com o vegetal, as práticas de cultivo, as condiçôes higiênicas durante o manuseio e processamento, a temperatura de armazenamento, entre outros fatores (ARTES et al., 2007).

Em laranja, a eliminação da proteção natural formada pelo flavedo e albedo promove alteraçôes fisiológicas, como senescência acelerada e mudanças metabólicas. Os frutos tornam-se mais suscetíveis ao ataque microbiológico, como consequência da possível perda de suco vesicular e ausência da proteção da casca (Pretel et al., 1998).

Assim, a utilização de embalagens com atmosfera modificada torna-se interessante pela influência nos processos fisiológicos e bioquímicos do vegetal minimamente processado, bem como na redução da proliferação microbiana, retardando a senescência.

A modificaçáo da atmosfera em uma embalagem plástica pode ser estabelecida de forma passiva ou ativa. A atmosfera passiva se estabelece pela própria respiração do produto, enquanto em atmosfera modificada ativa é realizada uma injeção de composição gasosa no momento em que o produto é embalado (Lana e Finger, 2000).

Embora as embalagens sob atmosfera modificada de frutas minimamente processadas possam aumentar a vida útil desses produtos, elas não conseguem superar os efeitos negativos causados pelo aumento da temperatura. SANDhya (2010) aponta que o manejo adequado da temperatura durante o preparo dos produtos e a refrigeração durante a distribuição e a comercialização são essenciais para a manutenção da qualidade.

Este trabalho teve como objetivo determinar a influência da embalagem com atmosfera modificada na manutenção da qualidade química, microbiológica e sensorial de laranja 'Pêra' minimamente processada armazenada sob refrigeração.

\section{MATERIAL E MÉTODOS}

Laranjas 'Pêra' provenientes de pomares comerciais da regiăo de Engenheiro Coelho (SP) foram lavadas com detergente neutro, sanificadas em água com $200 \mathrm{mg} \mathrm{L}^{-1} \mathrm{de}$ cloro e resfriadas a $6^{\circ} \mathrm{C}$ por 12 horas. Após esse período os frutos foram submetidos ao tratamento hidrotérmico, conforme descrito abaixo, e posteriormente descascados.
O tratamento hidrotérmico foi realizado colocando-se os frutos em água a $50 \pm 1^{\circ} \mathrm{C}$ por oito minutos (ARruda et al., 2008). Em seguida, procedeu-se o descascamento, realizando-se uma abertura na região peduncular do fruto com auxílio de uma faca, seguindo-se a retirada manual do flavedo mais o albedo.

As laranjas descascadas foram acondicionadas em sacos de polipropileno de $32 \mu \mathrm{m}$ sob dois sistemas de modificação da atmosfera (passiva e ativa $-5 \% \mathrm{O}_{2}+10 \%$ $\left.\mathrm{CO}_{2}+85 \% \mathrm{~N}_{2}\right)$. Laranjas acondicionadas em bandeja de poliestireno expandido revestida por filme de PVC $20 \mu \mathrm{m}$ foram utilizadas como controle. O armazenamento foi realizado a $6{ }^{\circ} \mathrm{C}$ por nove dias e a $12^{\circ} \mathrm{C}$ por 12 dias. Dessa forma, constituíram-se três tratamentos por temperatura, sendo: T1 - PVC (laranjas acondicionadas em bandeja de poliestireno expandida revestida por filme de PVC); T2- Passiva (laranjas acondicionadas em filme de polipropileno de $32 \mu \mathrm{m}$ sob atmosfera modificada passiva); T3 Ativa (laranjas acondicionadas em filme de polipropileno de $32 \mu \mathrm{m}$ sob atmosfera modificada ativa: $5 \% \mathrm{O}_{2}+10 \%$ $\mathrm{CO}_{2}+85 \% \mathrm{~N}_{2}$ ).

As laranjas minimamente processadas foram avaliadas quanto às características químicas, microbiológicas e sensoriais. Foram determinados os níveis de etanol, acetaldeído, e atividade da enzima peroxidase, além do monitoramento da composiçáo gasosa do interior das embalagens.

As características químicas avaliadas foram: teor de sólidos solúveis ( $\left.{ }^{\mathrm{B}} \mathrm{Brix}\right)$, acidez titulável (\% ácido cítrico) e ácido ascórbico ( $\left.\mathrm{mg} 100 \mathrm{~g} \mathrm{~g}^{-1}\right)$, de acordo com CarvalHo et al. (1990). Adicionalmente, foi calculada a relação sólidos solúveis: acidez titulável ("ratio").

Em relação às características microbiológicas foram determinados contagem total de bactérias psicrotróficas, coliformes totais e a $45^{\circ} \mathrm{C}$, bolores e leveduras, contagem total de bactérias anaeróbias segundo método proposto por Silva et al. (2001) e Salmonella pela utilização do kit '1-2 test', fabricado pela BioControl/USA.

Quanto às análises sensoriais, aplicou-se um teste de aceitação com escala hedônica estruturada de 7 pontos, sendo 7 = gostei muitíssimo; $6=$ gostei muito; $5=$ gostei; 4 = não gostei/nem desgostei; 3 = desgostei; 2 = desgostei muito; 1 = desgostei muitíssimo. A nota 4 foi considerada como limite de aceitabilidade do produto. Foram avaliados os atributos aparência, aroma e sabor do produto. A equipe sensorial foi composta por 30 provadores não-treinados.

Os teores de etanol e acetaldeído foram determinados de acordo com o método adaptado de Davis e Chace JúNIOR (1969). Foram preparadas amostras padrôes de etanol e acetaldeído e $1 \mathrm{~mL}$ destas amostras contendo de 100 a $6000 \mu \mathrm{g}$ de etanol e 5 a $43 \mu \mathrm{g}$ de acetaldeído foram colocados em frascos de $40 \mathrm{~mL}$, os quais foram mantidos em banho-maria a $50{ }^{\circ} \mathrm{C}$ por 30 minutos. Decorrido este tempo, $1 \mathrm{~mL}$ do espaço livre do frasco foi coletado com uma seringa Gastight marca Hamilton de $2,5 \mathrm{~mL}$ e injetado no cromatógrafo a gás equipado com detector de 
ionização de chama (FID) e coluna Porapack N de 1,8 m, para estabelecimento da curva-padrão. As configuraçóes do cromatógrafo foram: forno: $140^{\circ} \mathrm{C}$ durante 8 minutos. Após esse tempo, aumento de $20^{\circ} \mathrm{C}$ a cada minuto até atingir $180^{\circ} \mathrm{C}$, ficando nesta temperatura por $2 \mathrm{mi}-$ nutos para limpeza da coluna; injetor: $150^{\circ} \mathrm{C}$; detector: $180^{\circ} \mathrm{C}$; pressão: $190 \mathrm{kPa}$ (constante) e fluxo de $\mathrm{N}_{2}$ de $70 \mathrm{~mL} \mathrm{~min}{ }^{-1}$. Alíquotas de $1 \mathrm{~mL}$ de suco de laranja foram colocadas em frascos de $40 \mathrm{~mL}$, os quais foram mantidos em banho-maria a $50{ }^{\circ} \mathrm{C}$ por 30 minutos. Decorrido este tempo, $1 \mathrm{~mL}$ do espaço livre do frasco foi coletado com uma seringa Gastight marca Hamilton de 2,5 mL e injetado no cromatógrafo. Os teores de acetaldeído e de etanol das amostras foram calculados correlacionando as respectivas áreas cromatográficas com aquelas obtidas nas curvas-padrão. Os resultados foram expressos em $\mu \mathrm{g} \mathrm{g}^{-1}$.

Para determinação da atividade da peroxidase - POD (EC 1.11.1.7) amostras de laranja foram homogeneizadas em tampáo fosfato de potássio $0,2 \mathrm{M}, \mathrm{pH}$ 6,7 e centrifugadas a $9520 \mathrm{xg}$ por 10 minutos a $4{ }^{\circ} \mathrm{C}$. O sobrenadante foi utilizado para determinação da atividade da peroxidase pelo método de Allain et al. (1974), com leitura em 505 nm. Os resultados foram expressos em $\mu$ moles de $\mathrm{H}_{2} \mathrm{O}_{2}$ decomposto $\mathrm{min}^{-1}$.

Para monitoramento da composição gasosa foram fixados septos de silicone em cada embalagem, através dos quais foram coletadas amostras de gases do seu interior. Utilizou-se analisador de gases marca PBI-Dansensor, modelo Check Mate, o qual retira aproximadamente 2 $\mathrm{mL}$ de gás por amostragem. Os resultados foram expressos em $\% \mathrm{O}_{2}$ e $\% \mathrm{CO}_{2}$.

O delineamento experimental foi inteiramente casualizado em esquema fatorial (embalagens $\mathrm{x}$ tempo de armazenamento) para cada temperatura de armazenamento, com três repetiçóes por tratamento, sendo cada repetição composta por três frutos. Para análise sensorial o delineamento foi em blocos incompletos casualizados. Os resultados foram submetidos à análise de variância e comparação de médias pelo teste de Tukey a 5\% (Gomes, 1982).

\section{RESULTADOS E DISCUSSÃO}

Os teores de sólidos solúveis das laranjas minimamente processadas não foram afetados pela embalagem, apenas pelo tempo de armazenamento. Houve redução de apro- ximadamente $10 \%$ durante o armazenamento a 6 e a 12 ${ }^{\circ} \mathrm{C}$ (Tabela 1), indicando provável consumo destes compostos pelo processo respiratório durante o armazenamento. Estes resultados não estão de acordo com Donadon et al. (2004) e Pretel et al. (1998), os quais observaram estabilidade nos teores de sólidos solúveis em laranja minimamente processada ao longo do armazenamento.

No presente trabalho, nas laranjas armazenadas a $12^{\circ} \mathrm{C}$ houve redução nos teores de sólidos solúveis a partir do terceiro dia, enquanto a $6^{\circ} \mathrm{C}$ a redução foi significativa somente a partir do sexto dia de armazenamento.

Quanto aos teores de acidez, os valores situaram-se entre $0,48 \%$ e $0,54 \%$ de ácido cítrico (dados não apresentados), para as laranjas a 6 e a $12^{\circ} \mathrm{C}$, não havendo efeito da embalagem nem do tempo de armazenamento. Pretel et al. (1998) também observaram valores estáveis de acidez durante o armazenamento de laranjas minimamente processadas. No entanto, Rocha et al. (1995) observaram decréscimo de $36 \%$ na acidez titulável de laranjas minimamente processadas armazenadas a $4{ }^{\circ} \mathrm{C}$ por oito dias.

A relação entre sólidos solúveis e acidez titulável, também conhecida como "ratio", correlaciona-se com o sabor. Sucos com "ratio" entre 14 e 16 são os mais apreciados pelos consumidores devido ao equilíbrio, em termos sensoriais, entre os teores de açúcares e ácidos (PozzAN e Triboni, 2005). Nesse trabalho os valores de "ratio" situaram-se entre 16,37 e 22,44 (dados não apresentados) e náo foram influenciados pela embalagem nem pelo tempo de armazenamento.

O teor de ácido ascórbico das laranjas minimamente processadas não foi influenciado pela embalagem nem pelo tempo de armazenamento, mantendo-se estável, com valores ao redor de $30 \mathrm{mg}^{100 \mathrm{~g}^{-1}}$ suco (dados não apresentados).

A estabilidade do teor de ácido ascórbico provavelmente esteja associada à proteçấo das vesículas de suco pela membrana do hesperídeo, assim como à temperatura de refrigeração. Em trabalhos com frutas cítricas minimamente processadas Donadon et al. (2004) e Vale et al. (2006) também observaram estabilidade, enquanto RoCHA et al. (1995) e PlazA et al. (2011) observaram redução nos teores de ácido ascórbico.

Em laranjas 'Shamouti' e minimamente processadas e armazenadas a $4{ }^{\circ} \mathrm{C}$ por 12 dias observou-se estabilidade do ácido ascórbico, enquanto em laranjas 'Salustiana' nas mesmas condições, a redução foi de $11,25 \%$ ao fim do armazenamento (Del Caro et al., 2004).

Tabela 1. Teor de sólidos solúveis ( $\left.{ }^{\circ} \mathrm{Brix}\right)$ de laranja 'Pêra' minimamente processada armazenada a $6{ }^{\circ} \mathrm{C}$ e a $12{ }^{\circ} \mathrm{C}$

\begin{tabular}{lcccccc|c|} 
Temperaturas de & \multicolumn{5}{c}{ Dias de armazenamento } \\
armazenamento & $\mathbf{0}$ & $\mathbf{3}$ & $\mathbf{6}$ & $\mathbf{9}$ & $\mathbf{1 2}$ & $\mathbf{C V}(\%)$ \\
\hline $6^{\circ} \mathrm{C}$ & $10,68 \mathrm{a}$ & $10,18 \mathrm{ab}$ & $9,50 \mathrm{~b}$ & $10,23 \mathrm{ab}$ & $9,82 \mathrm{~b}$ & 5,90 \\
$12^{\circ} \mathrm{C}$ & $10,68 \mathrm{a}$ & $9,29 \mathrm{~b}$ & $9,91 \mathrm{ab}$ & $9,56 \mathrm{~b}$ & & 6,45 & \\
\hline
\end{tabular}

Médias seguidas de mesma letra na linha não diferem entre si ao nível de $5 \%$ de probabilidade.

Os valores referem-se à média obtida entre os três tipos de embalagem. 
Os níveis de contaminação por bactérias anaeróbias e psicrotróficas e de bolores e leveduras foram bastante baixos em todos os tratamentos, atingindo no máximo 90 $\mathrm{UFC} \mathrm{g}^{-1}$ (dados não apresentados). Não foram detectados coliformes totais a $45^{\circ} \mathrm{C}$ nem Salmonella em nenhuma das amostras de todos os tratamentos. Estes resultados estão de acordo com os obtidos por Donadon et al. (2004) que verificaram baixos níveis de contaminação microbiológica em laranjas minimamente processadas.

A resolução RDC n. ${ }^{\circ} 12$ de 2 de janeiro de 2001 da Agência Nacional de Vigilância Sanitária do Ministério da Saúde, estabelece que frutas frescas preparadas (descascadas, selecionadas ou fracionadas) devem ter no máximo, 5 x $10^{2} \mathrm{NMP}$ de coliformes a $45^{\circ} \mathrm{C} \mathrm{g}^{-1}$ e devem ter ausência de Salmonella em $25 \mathrm{~g}$ de produto.

Em relação a coliformes totais e contagens totais de bactérias e de bolores e leveduras não há limites máximos estabelecidos pela legislação, porém é preconizado que alimentos contendo contagens da ordem de $10^{4}$ e $10^{5}$ UFC $\mathrm{g}^{-1}$ são impróprios para o consumo humano devido à perda do valor nutricional, alteraçóes organolépticas, riscos de deterioração e/ou presença de patógenos.

No presente trabalho, não ficou evidente o efeito da embalagem com atmosfera modificada nem da temperatura de armazenamento sobre o desenvolvimento microbiano. No entanto, é sabido que a temperatura de armazenamento determina a atividade respiratória do produto e, consequentemente as concentraçôes de gases do interior da embalagem, a qual influencia o comportamento do

Tabela 2. Características sensoriais $\left({ }^{1}\right)$ de laranja 'Pêra’ minimamente processada armazenada a $6^{\circ} \mathrm{C}$

\begin{tabular}{lccc}
$\begin{array}{l}\text { Dias de } \\
\text { armazenamento }\end{array}$ & Aparência & Aroma & Sabor \\
\hline 0 & $5,77 \mathrm{a}$ & $5,53 \mathrm{a}$ & $5,87 \mathrm{a}$ \\
\hline 3 & $4,89 \mathrm{c}$ & $4,89 \mathrm{~b}$ & $4,96 \mathrm{~b}$ \\
\hline 6 & $5,59 \mathrm{ab}$ & $4,49 \mathrm{~b}$ & $5,09 \mathrm{~b}$ \\
\hline 9 & $5,13 \mathrm{bc}$ & $4,73 \mathrm{~b}$ & $5,16 \mathrm{~b}$ \\
\hline 12 & $5,11 \mathrm{c}$ & $4,92 \mathrm{~b}$ & $5,33 \mathrm{~b}$ \\
\hline $\mathrm{CV}(\%)$ & 17,30 & 20,32 & 19,17 \\
\hline
\end{tabular}

Médias seguidas de mesma letra na coluna nấo diferem entre si ao nível de $5 \%$ de probabilidade. (') 7-gostei muitíssimo; 6- gostei muito; 5- gostei; 4- nem gostei/ nem desgostei; 3- desgostei; 2- desgostei muito; 1- desgostei muitíssimo. Os valores referem-se à média obtida entre os três tipos de embalagem. microrganismo. Além disso, a temperatura influencia a taxa de senescência dos produtos minimamente processados, modificando então o ambiente dos microrganismos.

Diante deste fato, podemos inferir que a boa qualidade microbiológica do produto está relacionada às características intrínsecas da laranja (baixo metabolismo, poucas transformaçôes fisiológicas e bioquímicas após a colheita) e às boas práticas de fabricação adotadas durante o processamento dos frutos.

A aparência das laranjas a $6{ }^{\circ} \mathrm{C}$ foi influenciada apenas pelo tempo de armazenamento $(\mathrm{p}<0,05)$, com reduçáo nos valores das notas atribuídas a esta variável. No entanto, no sexto dia, para estas laranjas, as notas de aparência foram superiores às do terceiro dia (Tabela 2).

A aparência das laranjas a $12^{\circ} \mathrm{C}$ também foi influenciada pelo tempo, com interação entre o período de armazenamento e as embalagens (Tabela 3). Em média, as notas atribuídas a estas laranjas foram reduzidas significativamente ao longo do tempo. Porém, as laranjas sob atmosfera modificada passiva e ativa tiveram redução nas notas de aparência até o sexto dia, seguido de um aumento. Em relação às tecnologias de embalagem, as laranjas acondicionadas em bandeja de poliestireno revestidas por PVC (controle) tiveram no sexto dia de armazenamento, notas de aparência superiores às laranjas sob atmosfera modificada passiva.

Embora o aumento das notas de aparência observado entre o terceiro e o sexto dia para laranjas a $6^{\circ} \mathrm{C}$ e entre o sexto e o nono dia para as laranjas sob atmosfera modificada passiva e ativa a $12{ }^{\circ} \mathrm{C}$ tenha sido significativo, em termos práticos, não significa que a aparência melhorou. Tal fato pode ser atribuído às possíveis imperfeições, intrínsecas ao processamento manual, que mantém maior ou menor quantidade de resquícios de albedo, assim como maior ou menor quantidade de injúrias, refletindo na aparência do produto recém-processado. Segundo comentários relatados por alguns provadores da equipe sensorial, as menores notas atribuídas à aparência estão associadas às injúrias no hesperídeo. Brando ressecamento também foi notado em todos os tratamentos, e provavelmente tenha sido o fator preponderante na redução dos valores das notas atribuídas à aparência do produto.

As notas atribuídas à aparência das laranjas minimamente processadas, tanto a 6 como a $12^{\circ} \mathrm{C}$, situaram-se

Tabela 3. Aparência ( $\left.{ }^{1}\right)$ de laranja 'Pêra' minimamente processada armazenada a $12^{\circ} \mathrm{C}$

\begin{tabular}{|c|c|c|c|c|c|}
\hline \multirow{2}{*}{ Tratamentos } & \multicolumn{5}{|c|}{ Dias de armazenamento a $12^{\circ} \mathrm{C}$} \\
\hline & 0 & 3 & 6 & 9 & CV(\%) \\
\hline PVC & $5,77 a A$ & $5,73 a A$ & $5,33 \mathrm{aAB}$ & $4,67 a B$ & 15,54 \\
\hline PP-passiva & $5,77 a A$ & $5,20 \mathrm{aA}$ & $4,00 \mathrm{bB}$ & $5,33 a A$ & 18,03 \\
\hline PP-ativa & $5,77 a A$ & $5,60 \mathrm{aA}$ & $4,50 \mathrm{abB}$ & $5,20 \mathrm{aA}$ & 20,47 \\
\hline $\mathrm{CV}(\%)$ & 16,22 & 16,07 & 22,67 & 20,44 & \\
\hline
\end{tabular}


dentro do limite de aceitabilidade durante o período de armazenamento; em média, entre o dia do processamento e o fim do armazenamento destas laranjas, houve redução ao redor de dois pontos na escala hedônica, variando de gostei muito a não gostei nem desgostei.

O sabor e o aroma das laranjas minimamente processadas armazenadas a $6^{\circ} \mathrm{C}$ e a $12^{\circ} \mathrm{C}$ não foram afetados pelas embalagens. Houve apenas pequena redução da aceitabilidade durante o armazenamento, porém sem atingir o limite mínimo estabelecido (Tabela 2 e 4).

Os teores de acetaldeído e de etanol das laranjas acondicionadas em filme PVC (controle) foram menores que dos demais tratamentos, exceto os teores de acetaldeído das laranjas armazenadas a $6^{\circ} \mathrm{C}$ (Figura 1).

As laranjas acondicionadas em filme de polipropileno armazenadas a $6^{\circ} \mathrm{C}$ sob atmosfera passiva e ativa tiveram aumento nos teores de etanol ao longo do tempo, e os maiores valores deste gás foram detectados nas laranjas sob atmosfera modificada ativa, as quais ficaram por mais tempo sob atmosfera com menores níveis de oxigênio (Figura 2). Os teores de acetaldeído também tiveram aumento, atingindo pico de produção no terceiro dia para as laranjas sob atmosfera ativa e no sexto dia para as laranjas dos demais tratamentos.

Tabela 4. Sabor e aroma $\left({ }^{1}\right)$ de laranja 'Pêra' minimamente processada armazenada a $12^{\circ} \mathrm{C}$

\begin{tabular}{lcc}
$\begin{array}{l}\text { Dias de } \\
\text { armazenamento }\end{array}$ & Aroma & Sabor \\
\hline 0 & $5,53 \mathrm{a}$ & $5,87 \mathrm{a}$ \\
\hline 3 & $5,07 \mathrm{a}$ & $5,16 \mathrm{~b}$ \\
6 & $4,50 \mathrm{~b}$ & $5,16 \mathrm{~b}$ \\
\hline 9 & $4,87 \mathrm{~b}$ & $4,89 \mathrm{~b}$ \\
CV(\%) & 21,10 & 18,75 \\
\hline
\end{tabular}

Médias seguidas de mesma letra na coluna não diferem entre si ao nível de 5\% de probabilidade.

(1) 7- gostei muitíssimo; 6- gostei muito; 5- gostei; 4- nem gostei/nem desgostei; 3desgostei; 2- desgostei muito; 1 - desgostei muitíssimo.

Os valores referem-se à média obtida entre os três tipos de embalagem.
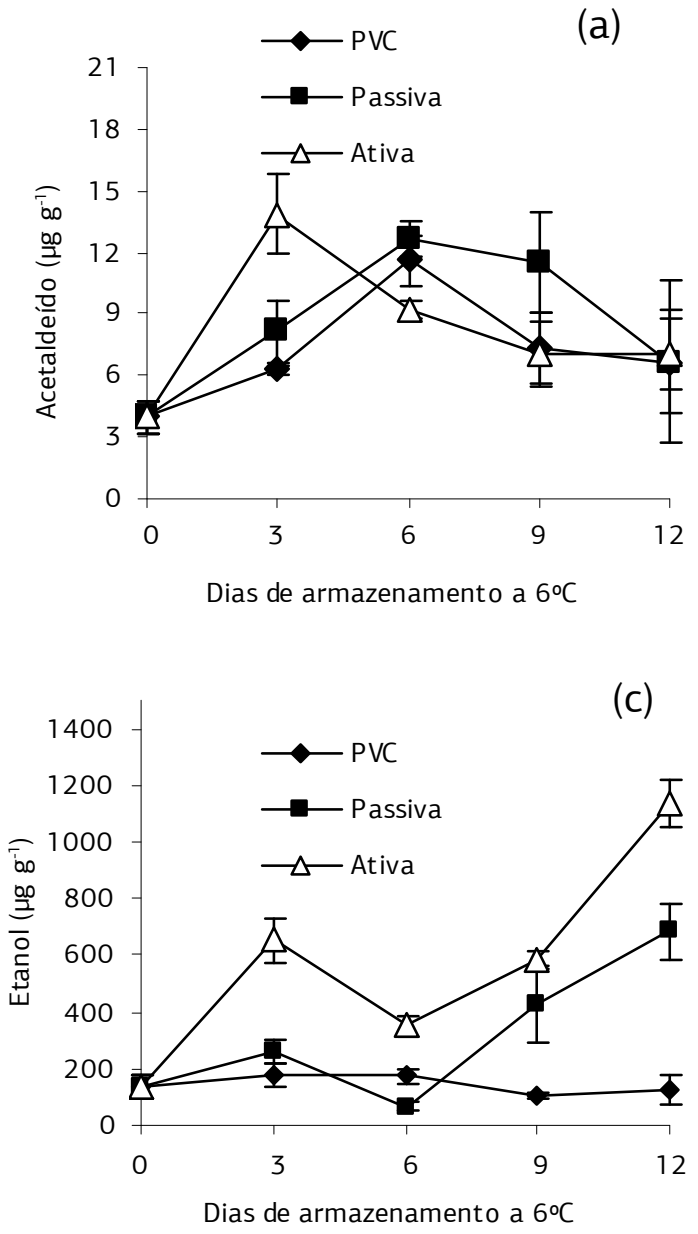

(b)

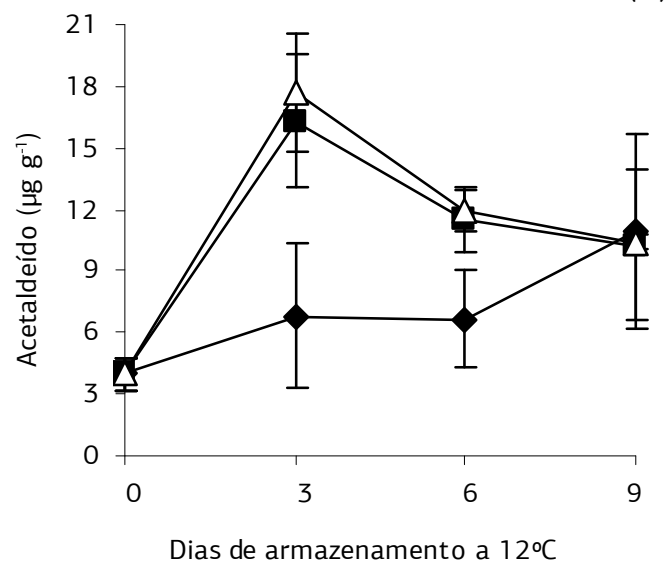

(d)

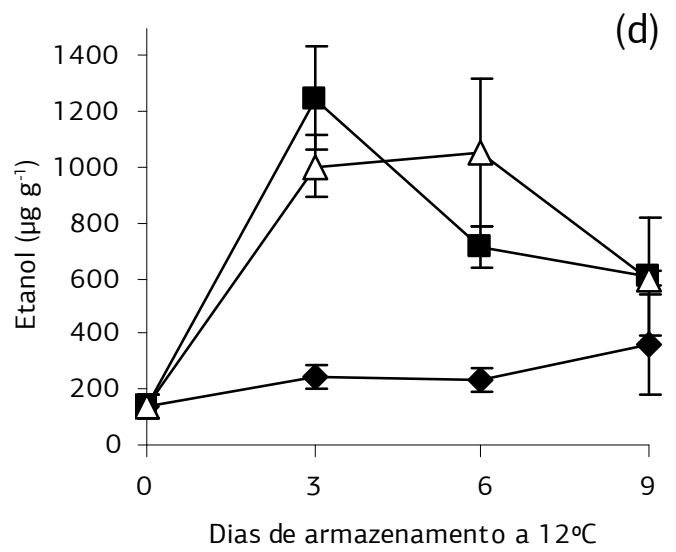

Figura 1. Teores de acetaldeído ( $\mathrm{a}$; b) e etanol $(\mathrm{c} ; \mathrm{d})$ de laranja 'Pêra' minimamente processada em função da embalagem com atmosfera modificada. As barras representam o desvio-padrão da média (três repetiçôes). PVC: laranjas acondicionadas em bandeja de poliestireno expandida revestida por filme de PVC; Passiva: laranjas acondicionadas em filme de polipropileno $32 \mu \mathrm{m}$ sob atmosfera modificada passiva; Ativa: laranjas acondicionadas em filme de polipropileno $32 \mu \mathrm{m}$ sob atmosfera modificada ativa $\left(5 \% \mathrm{O}_{2}+10 \% \mathrm{CO}_{2}+85 \% \mathrm{~N}_{2}\right)$. Cada símbolo representa o valor médio de três repetições. 


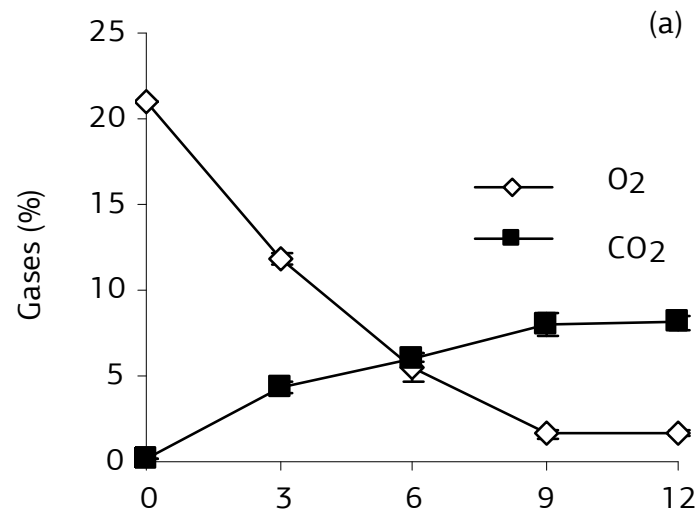

Dias de armazenamento a $6^{\circ} \mathrm{C}$

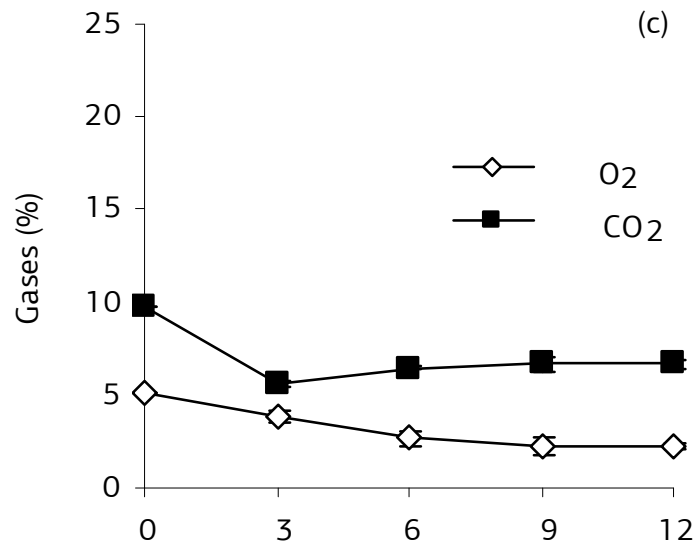

Dias de armazenamento a $6^{\circ} \mathrm{C}$

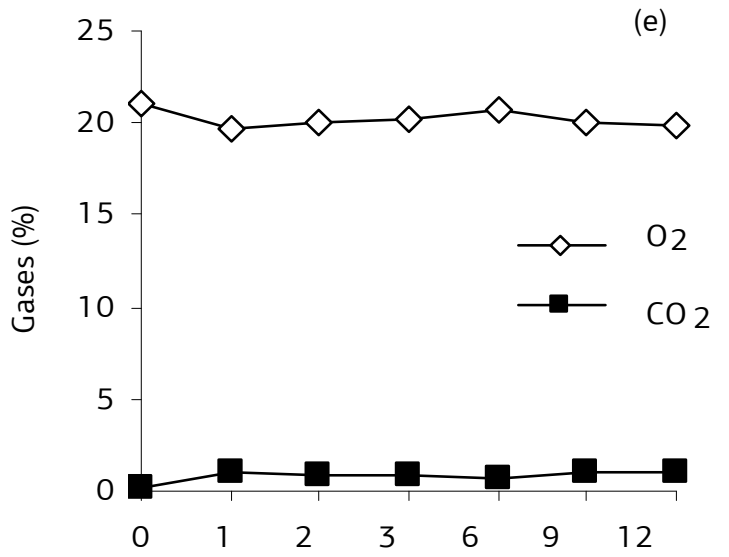

Dias de armazenamento a $6^{\circ} \mathrm{C}$

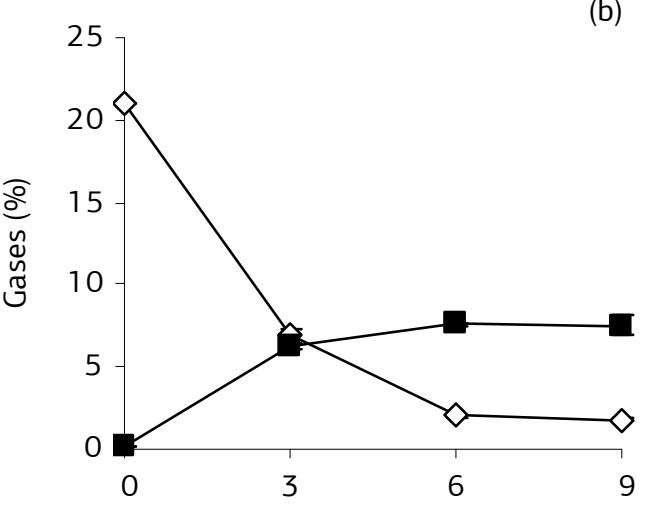

Dias de armazenamento a $12^{\circ} \mathrm{C}$

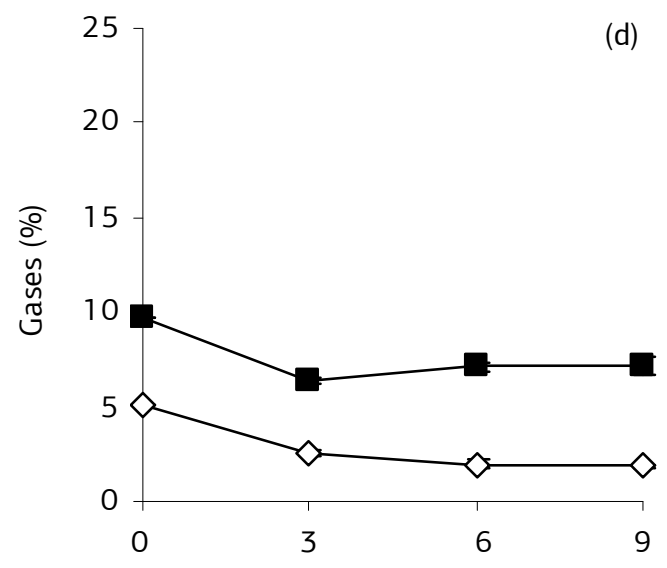

Dias de armazenamento a $12^{\circ} \mathrm{C}$

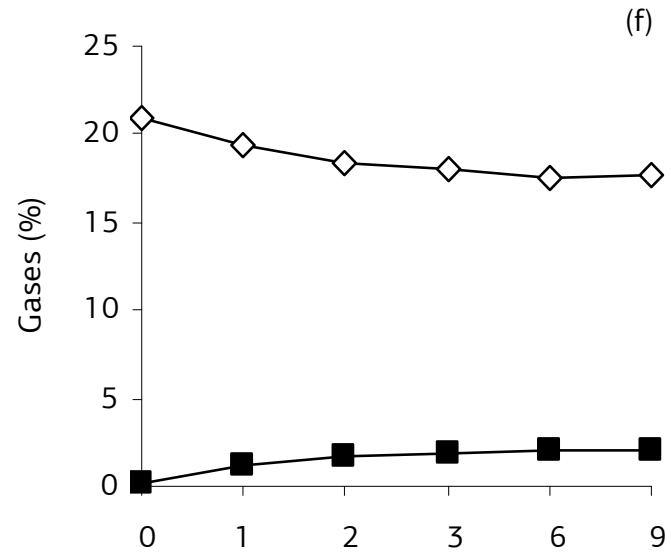

Dias de armazenamento a $12^{\circ} \mathrm{C}$

Figura 2. Composição gasosa (\%v/v) do interior das embalagens PP: saco de polipropileno sob atmosfera passiva (a;b) ou ativa (c;d) $\left(5 \% \mathrm{O}_{2}+10 \% \mathrm{CO}_{2}+85 \% \mathrm{~N}_{2}\right)$ e bandejas de poliestireno expandido revestida por filme de PVC (e;f) contendo laranjas minimamente processadas armazenadas a $6^{\circ} \mathrm{C}$ e a $12^{\circ} \mathrm{C}$. As linhas verticais representam o desvio-padrão da média (três repetições). 
As laranjas armazenadas a $12{ }^{\circ} \mathrm{C}$ tiveram pico na produçãa de etanol e acetaldeído no terceiro dia de armazenamento, seguido de decréscimo. Até o sexto dia de armazenamento nas laranjas sob atmosfera passiva e ativa, os níveis de acetaldeído e etanol foram significativamente superiores às laranjas acondicionadas em PVC.

O decréscimo nos níveis de acetaldeído observado a $6^{\circ} \mathrm{C}$ e $12{ }^{\circ} \mathrm{C}$ e de etanol observado a $12^{\circ} \mathrm{C}$, provavelmente seja decorrente de sua difusáo para o espaço livre da embalagem ou de sua conversão em outros compostos, conforme sugerido por Ke et al. (1995).

A concentração de acetaldeído foi muito menor em relação à concentração de etanol; a concentração de acetaldeído das laranjas dos diversos tratamentos e diferentes tempos de armazenamento foi no máximo de $19,75 \%$ da concentraçáo de etanol. Do total de acetaldeído e etanol quantificados no dia do processamento $\left(142,5 \mu \mathrm{L} \mathrm{L}^{-1}\right)$, o etanol contribuiu com mais de $97 \%\left(138,5 \mu \mathrm{L} \mathrm{L}^{-1}\right)$. Resultados semelhantes foram encontrados por ARTÉsHernández et al. (2007) em limóes 'Lisbon'. Os autores relatam que dentre os metabólitos fermentativos quantificados, o etanol contribuiu com mais de $88 \%$.

Os níveis de etanol e acetaldeído foram maiores a $12^{\circ} \mathrm{C}$, provavelmente devido às menores tensões de oxigênio a que os frutos foram expostos nesta temperatura e à maior atividade de piruvato descarboxilase e de álcool desidrogenase, enzimas-chave responsáveis pela respiração anaeróbica e pela produção de acetaldeído e etanol. Acúmulo de acetaldeído e etanol também foi reportado em laranjas minimamente processadas acondicionadas em filme de alta barreira, em que as tensões de oxigênio foram baixas (Pretel et al., 1998).

Neste trabalho, o acúmulo destes voláteis não alterou a qualidade sensorial das laranjas minimamente processadas, as quais tiveram notas referentes ao sabor e aroma dentro do limite de aceitabilidade (nota mínima 4) durante todo o período de armazenamento (Tabelas 2, 3 e 4). Ke e Kader (1990) reportam que laranjas 'Valência' intactas toleram concentraçóes de $0,25 \%$ de $\mathrm{O}_{2}$ por até 20 dias, sem alteração no sabor.

$A$ atividade da peroxidase náo foi influenciada pela tecnologia de embalagem nem pelo tempo de armazenamento, mantendo-se baixa, ao redor de $0,03 \mu$ moles de $\mathrm{H}_{2} \mathrm{O}_{2}$ decomposto min $^{-1} \mathrm{~g}^{-1}$ durante o armazenamento (dados não apresentados). Souza et al. (2006) verificaram pequena variação da atividade da peroxidase durante o armazenamento de mangas 'Keitt' minimamente processadas, sem influência do tipo de embalagem utilizada. Os valores de atividade enzimática avaliados por este autor foram em torno de $0,0017 \mu$ moles de $\mathrm{H}_{2} \mathrm{O}_{2}$. Antoniolli et al. (2003) verificou diminuição linear na atividade peroxidásica ao longo do tempo de armazenamento de abacaxi minimamente processado tratado com $\mathrm{CaCl}_{2}$.

A peroxidase, enzima indicadora de senescência de vegetais é importante do ponto de vista nutricional, de coloração e de sabor. A atividade desta enzima pode levar à destruição da vitamina $\mathrm{C}$ e descoloração de carotenóides e antocianinas, além de catalisar a degradação de ácidos graxos insaturados, com consequente formação de compostos voláteis que conferem sabor oxidado (LAMIKanRA, 2002). No entanto, não houve correlação da atividade desta enzima com a perda de qualidade da laranja minimamente processada.

A embalagem de polipropileno sob atmosfera modificada passiva ou ativa não resultou em ganho significativo nas características químicas, microbiológicas e sensoriais. Isto se deve à alta capacidade de conservação da laranja, evidenciando que esta fruta possui elevado potencial para ser utilizada como minimamente processada, dispensando o uso de embalagem de custo elevado.

\section{CONCLUSÃO}

A embalagem de poliestireno expandido revestida por filme de PVC $20 \mu \mathrm{m}$ foi táo eficiente quanto a embalagem de polipropileno $32 \mu \mathrm{m}$ sob atmosfera modificada passiva ou ativa em manter a qualidade da laranja minimamente processada.

A vida útil das laranjas minimamente processadas é de nove dias a $12^{\circ} \mathrm{C}$ e doze dias a $6^{\circ} \mathrm{C}$, limitada pela incidência de fungos na membrana do hesperídeo.

\section{REFERÊNCIAS}

ALLAIN, C.C.; POON, L.S.; CHAN, C.S.G.; RICHMOND, W.; FU, P.C. Enzymatic determination of total serum colesterol. Clinical Chemistry, v.120, p.470-475, 1974.

ANTONIOLLI, L.R.; BENEDETTI, B.C.; SOUZA FILHO, M.S.M. Efeito do cloreto de cálcio na qualidade do abacaxi 'Pérola' minimamente processado. Pesquisa Agropecuária Brasileira, v.38, p.1105-1110, 2003.

ARRUDA, M.C.; JACOMINO, A.P.; PINHEIRO, A.L.; RIBEIRO, R.V.; LOCHOSKI, M.A.; MOREIRA, R.C. Hydrotermal treatment favors peeling of 'Pêra' sweet orange and does not alter quality. Scientia Agricola, v.65, p.151-156, 2008.

ARTÉS, F.; GÓMEZ, P.A.; ARTÉS-HERNÁNDEZ, F. Physical, Physical, physiological and microbial deteroration of minimally fresh processed fruits and vegetables. Food Science and Technology International, v.13, p.177-188, 2007.

ARTÉS-HERNÁNDEZ, F; RIVERA-CABRERA, F.; KADER, A.A. Quality retention and potential shelf-life of fresh-cut lemons as affected by cut type and temperature. Postharvest Biology and Technology, v.43, p.245-254, 2007.

BRASIL. Resolução RDC n. 12 de 02 de janeiro de 2001 da Agência Nacional de Vigilância Sanitária. Dispões sobre o Regulamento técnico sobre padróes microbiológicos para alimentos. Diário 
Oficial da República Federativa do Brasil, Brasília, DF, 10 de jan. 2001.

CARVALHO, C.R.L.; MANTOVANI, D.M.B.; CARVALHO, P.R.N.; MORAES, R.M.M. Análise química de alimentos. Campinas: ITAL, 1990. 121p. (Manual Técnico)

CHITARRA, M.I.F.; CHITARRA, A.B. Pós-colheita de frutos e hortaliças: fisiologia e manuseio. 2 ed. Lavras: UFLA, 2005. 785p.

DAVIS, P.L.; CHACE JÚNIOR, W.G. Determination of alcohol in citrus juice by gas chromatographic analysis of headspace. HortScience, v.4, p.117-119, 1969.

DEL CARO, D.C.; PIGA, A.; VACCA, V.; AGABBIO, M. Changes of flavonoids, vitamin $\mathrm{C}$ and antioxidant capacity in minimally processed citrus segments and juices during storage. Food Chemistry, v.84, p.99-105, 2004.

DONADON, J.R.; DURIGAN, J.F.; SOUZA, B.S.; TEIXEIRA, G.H.A.; SANCHES, J. Efeito do tipo de descasque e da temperatura de armazenamento na qualidade de laranjas 'Pêra' minimamente processadas. Revista Brasileira de Fruticultura, v.26, p.419-423, 2004 .

GOMES, F.P. Curso de estatística experimental. 10.ed. Piracicaba: Nobel, 1982. 430p.

KE, D.; KADER, A.A. Tolerance of 'Valencia' oranges to controlled atmospheres as determined by physiological responses and quality atributes. Journal of the American Society for Horticultural Science, v.115, p.779-783, 1990.

KE, D.; YAHIA, E.; HESS, B.; ZHOU, L.; KADER, A.A Regulation of fermentative metabolism in avocado fruit under oxygen and carbon dioxide stresses. Journal of the American Society for Horticultural Science, v.120, p.481-490, 1995.

LAMIKANRA, O. Fresh-cut fruits and vegetables: science, technology, and market. Boca Raton: CRC Press, 2002. 449p.
LANA, M.M.; FINGER, F.L. Atmosfera modificada e controlada. Aplicação na conservação de produtos hortícolas. Brasília: Embrapa Comunicação para Transferência de Tecnologia, 2000. 34p.

PLAZA, L.; CRESPO, I.; PASCUAL-TERESA, S..; ANCOS, B.; SÁNCHEZ-MORENO, C.; MUÑOZ, M.; CANO, M.P. Impact of minimal processing on orange bioactive compounds during refrigerated storage. Food Chemistry, v.124, p.646-651, 2011.

POZZAN, M.; TRIBONI, H.R. Colheita e qualidade do fruto. In: MATTOS JÚNIOR, D.; DE NEGRI, J.D.; PIO, R.; POMPEU JUNIOR, J. (Ed.). Citros. Campinas: IAC; Fundag, 2005.cap.26, p.801-822.

PRETEL, M.T.; FERNÁNDEZ, P.S.; ROMOJARO, F.; MARTINEZ, A. The effect of modified atmosphere packaging on 'ready-to-eat'oranges. Lebensmittel.-Wissenschaft UndTechnologie, v.31, p.322-328, 1998.

ROCHA, A.M.C.N.; BROCHADO, C.M.; KIRBY, R.; MORAIS, A.M.M.B. Shelf-life of chilled cut orange determined by sensory quality. Food Control, v.6, p.317-322, 1995.

SANDHYA. Modified atmosphere packaging of fresh produce: Current status and future needs. LWT-Food Science and Technology, v.43, p.381-392, 2010.

SILVA, N.; JUNQUEIRA, V.C.A.; SILVEIRA, N.F.A. Manual de métodos de análise microbiológica de alimentos. 2ed. São Paulo: Varela, 2001. 317p.

SOUZA, B.S.; DURIGAN, J.F.; DONADON, J.R.; SOUZA, P.S. Mangas minimamente processadas amadurecidas naturalmente ou com etileno e armazenadas em diferentes embalagens. Revista Brasileira de Fruticultura, v.28, p.271-275, 2006.

VALE, A.A.S.; SANTOS, C.D.; ABREU, C.M.P.; CORREAA, A.D.; SANTOS, J.A. Alteraçóes químicas, físicas e físico-químicas da tangerina 'Ponkan' (Citrus reticulata Blanco) durante o armazenamento refrigerado. Ciência e Agrotecnologia, v.30, p.778-786, 2006. 